are also indebted to Dr. H. E. Dadswell, of the Forest Products Division, C.S.I.R., Melbourne, in whose laboratory the exploratory observations were made, for helpful discussions of the problem.

${ }^{2}$ Kerr, T., and Bailey, I. W., J. Arnold Arboretum, 15, 327 (1934).

${ }^{2}$ Preston, R. D., Phil. Trans. Roy. Soc., B 224, 131 (1934).

" Bailey, X. W., and Berkeley, E. E., Amer. J. Bot., 29, 231 (1942).

4 Preston, R. D., Proc. Leeds Phil. Soc., 3, No. 9, 552 (1939).

${ }^{5}$ Bailey, I. W., and Vestal, M. R., J. Arnold Arboretum, 18, 185 (1937),

${ }^{6}$ Preston, R. D., Proc. Roy. Soc., B 133, 327 (1943).

'Preston, R. D., Proc. Roy. Soc., B 134, 202 (1947).

${ }^{8}$ Wardrop, A. B., Internal Report Division Forest Products, C.S.I.R., Melbourne, Australia (1946)

${ }^{9}$ Coppick, S., and Fowler, W. T., Paper Trade J., 109, T.S. 135 (1939),

${ }^{20}$ Wardrop, A. B., and Dadswell, H. E., in the press.

\section{ABSORPTION OF ULTRASONIC WAVES IN LIQUIDS}

A WELL-ATTENDED discussion on this topic was held by the Acoustics Group of the Physical Society on November 13 at the Imperial College. The meeting was opened by the chairman, Mr. H. L. Kirke, who said that experimental work in this field had outstripped theory, and that he hoped experimental and theoretical workers would be brought together as a result of the discussion.

Mr. J. M.M. Pinkerton (Cavendish Laboratory, Cambridge) outlined the differences between experiment and the classical theories of Stokes ${ }^{1}$ and Kirchhoff ${ }^{2}$, first noted by Biquard ${ }^{3}$. The calculations had assumed that the absorption would be caused by viscosity and heat conduction respectively ; in liquids the heat conduction term is generally negligible in comparison with the viscosity term. But the experimental behaviour of gases is now accepted as due to a relaxation phenomenon, in the interchange of energy between internal and external degrees of freedom. The absorption $\alpha$ in the majority of liquids has been shown to obey the relation $\alpha / \nu^{2}=$ constant, where $\nu$ is the frequency of measurement. This is also found for gases when $\nu$ is much lower than the relaxation frequency. To pursue the work to higher frequencies and obtain highly accurate data a new method had seemed desirable; from war-time experience the pulse method had appeared to be the most suitable. The first results using this method had been published by Pellam and Galt in $1946^{4}$. Mr. Pinkerton's experiments had been made by the same method independently ${ }^{5}$. Results were presented in detail for water. $\alpha / \nu^{2}$ was found to be constant over the range 7-70 Mc./s., within one or two per cent at constant temperature. There is a fall in $\alpha / \nu^{2}$ of about nine times between freezing and boiling points. The observed absorption follows the expected temperature variation of Stokes' theory over the range $0^{\circ}-95^{\circ} \mathrm{C}$., although remaining always about three times too large. This is very remarkable.

The behaviour of other liquids, as judged from published data ${ }^{4-7}$, can be used to divide them into arbitrary classes: (1) liquids where $\alpha_{\text {obs. }} / \alpha_{\text {calc. }}$ is $10-1,500$, with a relatively small positive temperature coefficient of absorption ; (2) those for which $\alpha_{\text {obs./ }}$

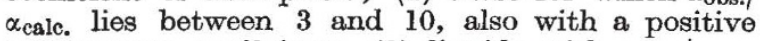
temperature coefficient; (3) liquids with $\alpha_{\text {obs. }} / \alpha_{\text {calc. }}$ between about 1 and 3 and a relatively large negative temperature coefficient; (4) very viscous liquids where the Stokes relation is obeyed. Liquids of classes (1) and (2) are non-associated organic liquids, and class (3) contains the primary alcohols and water, all typically associated liquids. Values of $\alpha_{\text {obs. }} / \alpha_{\text {calc. }}$ show a nearly regular progression from amyl alcohol to water. Mercury is not anomalous ${ }^{8}$, the theoretical absorption being shown up to 1,000 Mc./s. The consequences of a relaxation theory, as calculated by Kneser ${ }^{9}$, Mandelstam and Leontovitsch ${ }^{10}$ and others, are $(a)$ a dispersion of the velocity, $(b)$ a maximum in the value of $u=\alpha \lambda$; this would correspond to $\alpha / \nu^{2}$ falling from the constant value observed at lower frequencies. Neither consequence has been verified experimentally. Various ways of estimating the relaxation frequency expected put it in the region of $10^{3} \mathrm{Mc} . / \mathrm{s}$. for benzene. Hence the lack of experimental proof of a relaxation effect might be accounted for, if the measurements had been made at too low frequencies.

The variation of absorption with concentration in mixtures shows the same distinction between associated and non-associated liquids in the few cases so far investigated. In the case of two pairs of associated liquids, there is an absorption maximum at an intermediate concentration. Four pairs of nonassociated liquids show an initial rapid fall, followed by an asymptotic approach to the absorption value of the less absorbing liquid. This can be explained semi-quantitatively by introducing four relaxation times for the mixture and calculating, on certain extreme simplifying assumptions, the mean overall relaxation time as a function of the molecular con. centration. The variation in relaxation time has then to account for the change in absorption. In no mixture investigated has a linear variation of absorption been found.

Dr. E. G. Richardson (King's College, Newcastleon-Tyne) said he had carried out measurements between $100 \mathrm{kc} . / \mathrm{s}$. and $1 \mathrm{Mc} . / \mathrm{s}$. He outlined the sources of error in many of the experimental techniques used in the past, stressing the undesirable effects of excessive amplitude, and of the diffraction phenomena which occur. The use of very low powers is desirable, and the pulse method fulfils this require. ment well. Measurements, using a hot-wire detector, of the diffraction pattern of a source at low frequencies have confirmed the absence of scattering, mentioned by Mr. Pinkerton. Measurements of the Doppler frequency shift of light scattered by various liquids had led Raman and $\mathrm{RaO}^{11}$ to the conclusion that the velocity of 'hypersonic' waves (identifiable with Debye heat waves) is less than that measured at low frequencies. He was uncertain if it could be shown that all the ultrasonic energy absorbed appears as heat. A method of measuring absorption at low frequencies by propagating waves in a tube might be developed. Prof. L. Tisza had suggested that the observed behaviour of liquids could be represented by the introduction of a second coefficient of viscosity ${ }^{12}$. This point was taken up by Dr. Temperley later in the discussion. Another theory, in which the compressibility is relaxational, has been developed for water by L. Hall ${ }^{13}$. Dr. Richardson was concerned that any theory to explain the absorption behaviour of liquids should not introduce too many arbitrary constants, incapable of being verified independently.

Dr. H. N. V. Temperley (Cavendish Laboratory) discussed the possibility of a coefficient of expansion viscosity. Mathematically this is easily defined, and was introduced in his calculations by Stokes. This coefficient had been shown by Maxwell to be zero for gases, but seems to have been ignored for liquids. There are several theoretical models which might be used to calculate the absorption, based on the idea 
of a potential cell. Such models can in all cases lead to a finite expansion viscosity. A relaxation time can be involved in the readjustment of the molecules in potential cells to a small change in external conditions. He thought that any explanation of the behaviour of water must explain the variation of both the viscosity and the absorption with temperature, since these are so closely related. The distinctions drawn between associated and non-associated liquids make it clear that different theories must be developed for the two cases.

In the discussion contributions were made by Dr. P. Vigoureux, Mr. Bayard, Mr. D. O. Sproule, Dr. J. Lamb, Mr. Ribchester and Mr. E. Bauer. Dr. Lamb referred to the theoretical papers by Dutta ${ }^{14}$, and Dutta and Ghosh ${ }^{15}$ on dispersion and absorption of ultrasonic waves in liquids, and measurements by Rapuano ${ }^{16}$ up to $250 \mathrm{Mc}$./s. Venkatswaran ${ }^{17}$ had not confirmed Raman and Rao's results for dispersion of hypersonic waves.

${ }^{1}$ Stokes, G. G., Trans. Camb. Phil. Soc., 8, 287 (1845).

2 Kirchhoff, G., Pogg. Ann., 134, 177 (1868).

${ }^{3}$ Biquard, P., Ann. de Physique, 6, 195 (1936).

"Pellam, J. R., and Galt, J. K., J. Chem. Phys., 14, 608 (1946).

${ }^{5}$ Pinkerton, J. M. M., Nature, 160, 128 (1947).

"Willard, G. W., J. Acous. Soc., 12, 438 (1941).

"Hunter, J. L., J. Acous. Soc., 13, 36 (1941).

${ }^{8}$ Ringo, G. R., Fitzgerald, J. W., and Hurdle, B. G., Phy8. Rev., 72, 87 (1947).

${ }^{9}$ Kneser, H. O., Ann. d. Phys., 32, 277 (1938).

${ }^{10}$ Mandelstam, 1., and Leontovitsch, M., J. Exp. Theor. Phys., 7, 438 (1937).

${ }^{11}$ Raman, C. V., and Rao, B. V. R., Nature, 135, 161 (1935).

12 Tisza, L., Phys. Rev., 61, 531 (1942).

${ }^{13}$ Hall, L., Phys. Rev., '11, 318 (1947).

14 Dutta, A. K., Trans. Bose Research Inst., 12, 115 (1936-87).

15 Dutta, A. K., and Ghosh, Trans. Bose Research Inst., 13, 30 (1937-38).

10 Rapuano, R. A., Phys. Rev., "72, 78 (1947).

17 Venkatswaran, C. S., Proc. Ind. Acad. Sci., 15, 371 (1942).

\section{FUTURE OF AGRICULTURE IN BRITAIN}

$I^{\mathrm{N}}$

a Friday evening discourse at the Royal Institution on October 31, Lord De La Warr discussed the prospects of British agriculture and how far it could help to moet the country's present problems of a shortage of dollars and the threat of an actual scarcity of food. The first essential, he said, is to decide the true nature of the trouble, whether it is a 'crisis' of temporary duration only or whether we are not rather being confronted with a fundamental change in our national economy. If the difficulties are merely short-term, it would seem that British agriculture has little contribution to make, since production has declined over the last two years both as regards acreage of tillage and livestock figures, and time will be needed to reverse this trend. Though increase of livestock may be the best way of farming to save dollars, the opportunity, which offered itself twelve months ago, of buying adequate feeding stuffs to do this had not been taken, so that the prospect of building up an animal population rapidly is not hopeful. During the last two years the whole world food situation has gone from bad to worse, and though this may be no one's fault, it must be admitted that interest in agricultural matters has been sadly lacking in the British nation as a whole. The word 'crisis' is, in fact, quite misleading, and its use has prevented us from realizing that the start we gained in the industrial revolution has run out and that cheap food and raw materials, with the consequent high standard of living to which we had become accustomed, can no longer be taken for granted. The idea that when the present 'crisis' ends we shall again be able to import all the food we require at a low price must be abandoned before we can hope to rebuild our shattered economy.

During the last five years before the War, Great Britain was importing on an average $£ 50$ million per annum more than it was exporting; that is, we had already begun to live beyond our means, and since then we have raised our standard of living. Countries such as Canada, Australia and South America, that in the past were mainly food producers, have been steadily industrializing themselves, thereby decreasing their demands for British exports. Great Britain is, in consequence, not likely to be in a financial or economic position to pay for importing as large a proportion of food as formerly, and may even have difficulty in exporting sufficient to pay for essential raw material to maintain her factories. It is questionable, moreover, whether the food is even available, assuming we had the money to pay for it. Besides the changes brought about by the industrialization of the great food-producing countries, there are those due to alterations in farming methods. The switchover from cereal growing to livestock production that has occurred in the 'dust bowl' areas of the United States and Canada means less grain available for human requirements. Furthermore, enormous increases in population are taking place in India and Africa, as well as a rise in the consumption per head in these countries, due to the efforts to improve the standards of health and nutrition among the native peoples.

Other factors may prove of importance in determ. ining future trends. The control of the tsetse fly and locust, for example, would open up new regions for agricultural development, which in their turn might temporarily offset this increased demand for food. On the other hand, the elimination of the mosquito would result in an even more rapid rise in population in many areas.

For the purpose of feeding the people of Great Britain, the products of British agriculture are, therefore, literally of vital importance. The increase of $£ 100$ millions of food by 1952 demanded by the Government is moderate from the point of view of the potentialities of the soil and the needs of the situation. In terms of the facilities now available, of labour, houses, machinery, fertilizers and feeding stuffs, however, the target is not likely to be reached unless the drive behind it is intensified. It is the country, not the farming industry, that will suffer if the necessary increased production is not attained, and the facts and figures available point to the strong possibility of real hunger being experienced during the next twelve months. However, the soil of Britain is capable of producing more. Four years ago, $1 \frac{1}{2}$ million acres more were under cultivation than to-day, and there were more pigs and sheep and about the same number of cattle.

More knowledge and better application of existing knowledge are needed. Means must be found for carrying over new information particularly to the small farmer, and an improvement in the national standard of education is probably the best solution to this problem. Compared with other countries, the farming efficiency in Britain is high; more is produced per head than in any other country in Europe, 